\title{
A Comparison of Complications and Success Rates after PCNL in Younger and Elderly Patients
}

\author{
Nadeem Iqbal, Aisha Hasan, Hajra Arshad Malik, Rabiyya Khan, Ahsan Nazar and Muhammad Athar Khawaja \\ Department of Urology and Kidney Transplant, Pakistan Kidney Institute, Shifa International Hospital, Islamabad, Pakistan
}

\begin{abstract}
Objective: To compare the outcomes of percutaneous nephrolithotomy (PCNL) across younger and elderly, especially PCNL complications in terms of modified Clavian grading system.

Study Design: Cros-sectional comparative study.

Place and Duration of Study: Department of Urology, Shifa International Hospital, Islamabad, from 2010 till 2018 December at a tertiary care hospital.

Methodology: Patients who underwent unilateral PCNL were reviewed group 1 (younger, age < 60 years) had 594 patients; while group 2 (elderly, age >60 years) had 137 patents. Information regarding complication and success rate were recorded by residents in proforma and then processed for statistical computations.

Results: There were total of 731 subjects. The mean age in group 1 was $39.7 \pm 11.2$ years and that of group B was $65.66 \pm 4.55$ years. The mean size for calculi in group 1 was $2.83 \pm 1.32 \mathrm{~cm}$ while in group 2 stone size reached $2.81 \pm 1.04 \mathrm{~cm}$. A total of 174 (23.8\%) complications and stone free rate of $81.8 \%$ (598/731) was recorded in this study. Overall when compared, no notable difference in complications, hospital duration and success rates was observed between the young and elderly age group.

Conclusion: Despite old age, the success rates and complications were not remarkably different from that of the younger subjects for prone PCNL.
\end{abstract}

Key Words: Percutaneous nephrolithotomy, Geriatrics, Renal stone, Complications.

How to cite this article: Iqbal N, Hasan A, Malik HA, Khan R, Nazar A, Khawaja MA. A Comparison of Complications and Success Rates after PCNL in Younger and Elderly Patients. J Coll Physicians Surg Pak 2020; 30(12):1316-1320 .

\section{INTRODUCTION}

Urolithiasis is a common ailment that affects all age groups in a population. Various studies from different areas have indicated that the incidence of uppertractstone disease has gradually been on the rise during last 50 years. ${ }^{1-4}$ This increasing trend of incidence and the prevalence of nephrolithiasis has been noted across North America, Europe, and Asia over time. It is estimated that the worldwide incidence of renal stones is about $1 \%$, and has affected $5 \%$ to $10 \%$ persons in the industrialised countries. ${ }^{5,6}$ There has been improvements in medical care over time leading to overall life expectancy, that can result in stone disease becoming relatively more common in the geriatric population as compared to the past. Some recent studies have shown that old age patients make almost 10 to $12 \%$ of all patients referrals to tertiary care hospitals for treatment of urolithiasis. ${ }^{7,8}$

Correspondence to: Dr. Nadeem Iqbal, Department of Urology and Kidney Transplant, Pakistan Kidney Institute, Shifa International Hospital, Islamabad, Pakistan

E-mail: dr_nadeemiqbal84@yahoo.com

Received: March 17, 2020; Revised: August 21, 2020;

Accepted: September 30, 2020

DOI: https://doi.org/10.29271/jcpsp.2020.12.1316
The advent of minimally invasive surgical techniques has shifted the paradigm regarding the surgical management of renal stones. With further improvement in these techniques, their efficacy and lower rates of complications have been established in young patients and further efforts are being underway to lower perioperative risks and further enhance effectuality and net results in young patients. ${ }^{9}$ However, such studies are very sparse in elderly age group owing to its low incidence and prevalence rates as discussed earlier. Diminished functional reserves in elder subjects and the accompanying comorbid conditions that exhibits with advancing age might trigger plethora of surgical risks across the elderly subjects. This, in turn, plays a vital role in expectations regarding the perioperative consequences, thereby shaping the surgeon's judgement to proceed. ${ }^{9,10}$

Data regarding comparisons of outcomes of PCNL across young age and old age is sparse, reported by very few centres globally. ${ }^{10}$

The objective of this study was to compare safety and success of PCNL in ageing (age $>60$ years old) and younger individuals (age $<60$ years old), according to the modified Clavian system.

\section{METHODOLOGY}

This was a retrospective review of the charts for patients that underwent unilateral PCNL from 2010 till 2018 December at Department of Urology, Shifa International Hospital, Islam- 
abad. Departmental and Ethical Board Review approval was taken prior to start of this academic work. Informed consent was acquired from all patients. Patients were arranged into two age groups including those $\leq 60$ years old (group 1 ) and those $\geq 60$ years (group 2). All the patients included in these groups underwent PCNL for treating renal stones $>2 \mathrm{~cm}$ in size and were above age of 18 years. Furthermore, only patients with preoperative CT scan images available for Guy's stone scoring were included in the study. Patients having positive urine cultures, deranged renal functions, history of open renal surgery on same side previously and bleeding disorders were excluded. In addition to this, those patients who did not have CT scan images preoperatively or were lost to follow up were also excluded from study.

Patients were initially diagnosed after taking full history and physical examination. Radiological investigations used for renal stone included X-ray KUB (Kidney ureter and bladder), ultrasound KUB (Kidney ureter and bladder) and computed tomography. Stone length (largest diameter) was measured in $\mathrm{cm}$. In cases of multiple stones, all stones individual measurements were taken and their sum was used. Once decision made for percutaneous nephrolithotomy (PCNL), a complete blood count (CBC), electrolytes, serum urea, creatinine and PT/APTT were done one day ahead of the PCNL procedure. Preoperatively one unit of blood was arranged after doing blood cross match and grouping, if need for transfusion arise during the surgery or after PCNL. Patients having positive urine cultures were treated preoperatively with antibiotics according to the culture and sensitivity reports of urine culture.

Various patients' factors were recorded including age, gender, American Society of Anesthesiology classification scores (ASA), stone size, location of the stone.

Intraoperative variables included site of entry, procedure time and type of postoperative drainage used. Postoperative end results including achieving status of patients being stone-free (SFS), residual fragments of stone, complications categorised on the basis of modified Clavian grading system. According to this classification, grades one and two account for insignificant minor complications and grades three and four represent major complications.

After inducing general anesthesia, open-end catheter was passed in the desired ureter up to renal stone in lithotomy then after patients' position being changed to prone, desired calyceal punctures were executed under fluoroscopic imaging utilizing $18 \mathrm{G}$ diamond-tipped needle. Then percutaneous tract was broadened up to 26-30 Fr (using sequential metallic dilators) at the surgeon's discretion. Stones were broken with pneumatic lithoclast, seized and pulled out using prong graspers. Perioperative stone clearance was assessed by antegrade nephrostography under fluoroscopy images. Double J stent was placed in all patients. In case of need, nephrostomy tube was also placed (removed in 2-3 days). Double J stents were removed after 2-4 weeks if there was complete stone clearance or very small residual fragment were detected on X-ray KUB on follow-up.

We had a protocol of performing X Ray KUB and USG (renal ultrasound) KUB after 48-72 hours after the procedure. Patients were labelled as to have achieved stone-free status (SFS) in case of complete stone clearance or if residual stones fragments having size less than $4 \mathrm{~mm}$ on X Ray KUB (Kidney ureter bladder). The Guy stone scoring, as propounded by Thomas et al. to forecast the net results of PCNL, was implemented. ${ }^{12}$ Guy score grades complexity of stones into 4 sub categories. Grade one depicts a lonely renal calculus that resides in lower/mid pole or renal pelvis with simple anatomy. Grade two denotes a lone upper pole renal calculus or if there are numerous calculi in kidney (in case of simple renal anatomy) or if there is a single stone in a kidney with aberrantanatomy.

Grade three encompasses cases having multiple stones in the presence of abnormal renal anatomy. Grade IV comprises of staghorn stones or if there is renal stones in patients suffering from spina bifida and in case of history of spinal cord injury.

Data was transferred to SPSS version 16; mean and standard deviation values were determined for the continuous variables. Frequency and percentages were utilised for representing categorical variables. Student's t-test was used for comparing the two age groups regarding continuous variables and Chi-square test was applied to compare categorical values across the two groups. A p-value of $<0.05$ was deemed as statistically significantvalue.

Table l: Demographic variables.

\begin{tabular}{|c|c|c|c|}
\hline & Group-1 & Group-2 & p-value \\
\hline Number & 594 & 137 & \\
\hline Mean Age & $39.7 \pm 11.2$ & $65.66 \pm 4.55$ & $<0.001$ \\
\hline Male & $423(71.21 \%)$ & $100(72.99 \%)$ & 0.7 \\
\hline Female & $171(28.79 \%)$ & $37(27.01 \%)$ & \\
\hline Right renal stone & $241(40.6 \%)$ & $61(44.53 \%)$ & \multirow{3}{*}{0.12} \\
\hline Left renal stone & $307(51.7 \%)$ & $72(52.55 \%)$ & \\
\hline Bilateral renal stone & $46(7.7 \%)$ & $4(2.92 \%)$ & \\
\hline Body mass index & $26.68 \pm 4.8$ & $26.49 \pm 4.6$ & 0.684 \\
\hline Mean stone size $(\mathrm{cm})$ & $2.83 \pm 1.32 \mathrm{~cm}$ & $2.81 \pm 1.04 \mathrm{~cm}$ & 0.4 \\
\hline Guys stone score & $1.63 \pm 0.9$ & $1.61 \pm 0.9$ & 0.883 \\
\hline Guys stone score 1 & 367 & 87 & \multirow{4}{*}{0.78} \\
\hline Guys stone score 2 & 130 & 26 & \\
\hline Guys stone score 3 & 49 & 14 & \\
\hline Guys stone score 4 & 48 & 10 & \\
\hline ASA class & & & \multirow{4}{*}{$<0.001$} \\
\hline ASA 1 & 407 (68.52\%) & $59(43.07 \%)$ & \\
\hline ASA 2 & $185(31.14 \%)$ & $73(53.3 \%)$ & \\
\hline ASA 3 & $2(0.34 \%)$ & $5(3.65 \%)$ & \\
\hline
\end{tabular}

\section{RESULTS}

Aggregate of 731 patients were eligible for analysis. Group 1 had 594 (81.3\%) patients while group 2 had 137 (18.7\%) patents. The mean age in group 1 was $39.7 \pm 11.2$ years and that of group B was $65.66 \pm 4.55$ years. The mean size for calculi in group 1 was $2.83 \pm 1.32 \mathrm{~cm}$ while in group 2 stone size reached $2.81 \pm 1.04 \mathrm{~cm}$. Patientage, stone size, gender distribution/loca- 
tion stone laterality are tabulated in Table I. Among the two groups, body mass index (BMI), distributionlocation of stone in kidney, location, side of stone, anomalous kidneys presence of staghorn (partial or complete) stones and GSS were similar.

Table II: Details of procedure outcomes.

\begin{tabular}{|c|c|c|c|}
\hline & Young age & Old age & p-value \\
\hline Stone free rate & $483(81.3 \%)$ & $115(83.9 \%)$ & 0.472 \\
\hline Residual stones & $111(18.7 \%)$ & $22(16.1 \%)$ & 0.5 \\
\hline $\begin{array}{l}\text { Mean operative } \\
\text { time }\end{array}$ & $128.04 \pm 37.54$ & $131.30 \pm 34.79$ & 0.353 \\
\hline Nephrostomy tube & $349(58.75 \%)$ & $80(58.39 \%)$ & 0.939 \\
\hline Re-Do PCNL & $8(1.35 \%)$ & $6(4.38 \%)$ & 0.020 \\
\hline $\begin{array}{l}\text { Ancillary } \\
\text { procedures } \\
\text { Miscellaneous } \\
\text { ESWL } \\
\text { PCNL } \\
\text { None } \\
\text { PCNL+ESWL } \\
\text { DJ stent* } \\
\text { Flexi cystoscopy } \\
\text { RPUG** }\end{array}$ & $\begin{array}{c}111(18.68 \%) \\
34(5.72 \%) \\
103(17.34 \%) \\
8(1.35 \%) \\
429(72.22 \%) \\
8(1.35 \%) \\
6(1.01 \%) \\
4(0.67 \%) \\
2(0.33 \%)\end{array}$ & $\begin{array}{c}31(22.62 \%) \\
5(3.65 \%) \\
31(22.63 \%) \\
6(4.38 \%) \\
93(67.88 \%) \\
2(1.46 \%) \\
0 \\
0 \\
0\end{array}$ & 0.138 \\
\hline \multirow{6}{*}{$\begin{array}{l}\text { Overall } \\
\text { Complications } \\
\text { Grade } 1 \\
\text { Grade } 2 \\
\text { Grade } 3 \\
\text { Grade } 4 \\
\text { No complication }\end{array}$} & $143(24.07 \%)$ & $31(22.62 \%)$ & \multirow{6}{*}{0.458} \\
\hline & $71(11.95 \%)$ & $12(8.76 \%)$ & \\
\hline & $49(8.25 \%)$ & $12(8.76 \%)$ & \\
\hline & $21(3.54 \%)$ & $5(3.65 \%)$ & \\
\hline & $2(0.34 \%)$ & $2(1.46 \%)$ & \\
\hline & $451(75.93)$ & $106(77.37 \%)$ & \\
\hline Hospital stay & $3.07 \pm 1.11$ & $3.26 \pm 1.08$ & 0.061 \\
\hline Analgesic doses & $4.9 \pm 3.1$ & $5.4 \pm 4.1$ & 0.114 \\
\hline
\end{tabular}

The overall mean operative time was $128.67+37.07$ minutes. On comparison across the two groups, no notable difference was found for the studied variables (Table II). Majority of the renal access tracts were accomplished at the lower pole $(400 / 594=67.3 \%$ in group 1 and $95 / 137=69.34 \%$ in group 2$)$. Overall stone free rate of $81.8 \%$ (598/731) was recorded in this study. While the remaining 133 (18.2\%) patients had residual stones. Relook PCNL wasneeded in 14 (1.92\%) patients and 134 patients $(18.3 \%)$ required ancillary shock wave lithotripsy (SWL) for achieving complete stone clearance.

Mean preoperative hemoglobin levels were $13.8 \pm 1.91 \mathrm{~g} / \mathrm{dl}$ and $13.8 \pm 2.08 \mathrm{~g} / \mathrm{dl}$ in group 1 and 2 respectively. Postoperative hemoglobin levels were $12.8 \pm 2.3 \mathrm{~g} / \mathrm{dl}$ and $12.2 \pm 2.4 \mathrm{~g} / \mathrm{dl}$ in group 1 and 2 respectively. Similarly preoperative creatinine were $1.15 \pm 0.8 \mathrm{mg} / \mathrm{dl}$ and $1.05 \pm 0.62 \mathrm{mg} / \mathrm{dl}$ in two groups respectively. While postoperative creatinine values were $1.2 \pm 0.9$ $\mathrm{mg} / \mathrm{dl}$ and $1.1 \pm 0.9 \mathrm{mg} / \mathrm{dl}$ in the two groups, respectively. The mean $( \pm S D)$ hospital stay in days was $3.1 \pm 1.1$ days. Although hospital stay was a bit longer in the group-2; however, no significant difference was observed across the two groups (Table II). A total of $174(23.8 \%)$ complications were recorded in our study. Moreover, complications distribution hinged on modified Clavian grading classification was similar among these two age groups (Table III). Ratio of minor and major complications were recorded as maintained by this classification. It was observed that they were similar in the two age groups when categorised with respect to Guy's stone score (GSS). Thirty patients (4.1\%) underwent transfusion. There was no difference in statistical terms between the two age groups (Table III). overall 31/731 (4.2\%) patients had sepsis post PCNL. No significant difference was noticed across these age groups with reference to this important complication (Table III).

\begin{tabular}{|c|c|c|c|c|}
\hline $\begin{array}{l}\text { Complication } \\
\text { grade }\end{array}$ & Type complication & Young age & Old age & p-value \\
\hline 1 & Fever & $22(3.7 \%)$ & $3(2.2 \%)$ & 0.19 \\
\hline 1 & $\begin{array}{l}\text { lleus without need NG } \\
\text { tube }\end{array}$ & $7(1.2 \%)$ & $2(1.5 \%)$ & \\
\hline 1 & $\begin{array}{l}\text { Urine leak puncture } \\
\text { wound site and } \\
\text { perinephric collection }\end{array}$ & $32(5.4 \%)$ & $\begin{array}{c}6 \\
(4.38 \%)\end{array}$ & 0.249 \\
\hline 1 & Transient hematuria & $57(9.6 \%)$ & $\begin{array}{c}15 \\
(10.9 \%)\end{array}$ & \\
\hline 1 & $\begin{array}{l}\text { Perirenal hematoma } \\
\text { (conservative } \\
\text { observation only) }\end{array}$ & $9(1.5 \%)$ & $3(2.2 \%)$ & \\
\hline 2 & Transfusion & $\begin{array}{c}24 \\
(4.04 \%) \\
\end{array}$ & $\begin{array}{c}6 \\
(4.38 \%) \\
\end{array}$ & 0.269 \\
\hline 2 & Sepsis & $25(4.2 \%)$ & $\begin{array}{c}6 \\
(4.38 \%) \\
\end{array}$ & 0.276 \\
\hline 2 & $\begin{array}{l}\text { lleus needing } \\
\text { nasogastric tube }\end{array}$ & $2(0.34 \%)$ & $0(0 \%)$ & \\
\hline 3 & $\begin{array}{l}\text { Perforation upper } \\
\text { tract }\end{array}$ & $17(2.9 \%)$ & $5(3.6 \%)$ & \\
\hline 3 & Pneumothorax & $1(0.17 \%)$ & $0 \%$ & \\
\hline 3 & $\begin{array}{l}\text { Hydrothorax needing } \\
\text { chest tube }\end{array}$ & $1(0.17 \%)$ & $0 \%$ & \\
\hline 3 & Hemothorax & $0 \%$ & $0 \%$ & \\
\hline 3 & Bowel injury & $0 \%$ & $0 \%$ & \\
\hline 3 & Perinephric abscess & $1(0.17 \%)$ & $0 \%$ & \\
\hline 3 & $\begin{array}{l}\text { Renal vascular injury } \\
\text { requiring } \\
\text { angioembolisation }\end{array}$ & $1(0.17 \%)$ & $0 \%$ & \\
\hline 4 & $\begin{array}{l}\text { Acute renal failure } \\
\text { needing dialysis }\end{array}$ & $1(0.17 \%)$ & $1(0.7 \%)$ & \\
\hline 4 & $\begin{array}{l}\text { Septic shock ICU } \\
\text { manage }\end{array}$ & $1(0.17 \%)$ & $0 \%$ & \\
\hline 5 & Death & $0 \%$ & $0 \%$ & \\
\hline
\end{tabular}

\section{DISCUSSION}

The treatment outcome in patients with urinary stones might be affected by age factor. However owing to the modern endoscopic techniques (PCNL/URS=ureteroscopy) it seems easy, safe and an effective tool of treatment even in aged population. ${ }^{11,12}$ However, more precautions are recommended to be taken for patients at farther end of age. In developing countries like Pakistan where PCNL has not been much common in every center (in last decade), the use of this modality in elderly patients might be a challenging task as compared to the young age. $^{11-14}$

Sahin et al. noted that the stone-free rate in old age patients was almost similar to that obtained in the patients with younger age despite the fact that old age group had somewhat higher stone burden (1077.92 $\mathrm{mm}^{2}$ vs. $920.85 \mathrm{~mm}^{2}$ ). They concluded that 
PCNL was equally effective in geriatric patients, in the absence of any inflated rates of complications or need for transfusing blood or extended hospital stay. They were of the opinion that it is a secure and efficacious method for treating renal stone in the ageing patients, even in cases of lone kidney or complex calculi. ${ }^{15}$ However, they had the deficiency of grading the complications. The complications in present study were categorised according to modified Clavian grading classification. This categorisation provides an opportunity to report complications without ambiguity and with uniformity. We noted no differences in terms of procedural success rates and complication rates (Tables II and III).

Okeke et al. mentioned that the difference between the young and old age groups for the end result of the PCNL was statistically unsubstantial. However, they noted a significantly higher hospital stay (5 vs. 4.1 days) in elderly age group. The hospital stay was 3.07 vs. 3.26 days for young and old age groups respectively $(p=0.061)$ in this study. This might be due to better preoperative preparation and perioperative care which may vary from surgeon to surgeon, institute to institute and the patient population presenting to a particular centre. ${ }^{16}$

In a recent study it was concluded that performing tubeless procedure was as safe and efficacious as standard tubed procedure in the old age population. It is said to have its advantages in this class of patients, for instance shorter period of hospitalization, fewer analgesic necessity, and quick mobilization. ${ }^{17}$ However, they had smaller sample size and they had also not taken into account the grades of complications (which might affect hospital stay). No dissimilarity was noted in terms of hospital time duration across the two age grouping irrespective of the fact that the patients underwent tubeless or tubed PCNL in either age group. Perhaps length of stay is influenced also by complications (even minor grade).A surgeon might be more careful even in clavien grade 1 or 2 complications. Here, it is important to note that the operating surgeon's experience with the procedure is also important., This might affect different attitude of surgeon and the patients regarding length of stay. ${ }^{18}$

Kumar et al. retrospective compared the outcomes of PCNL in different age groups. They observed fever in $11.5 \%$ of their patients after PCNL. While bleeding was present in $9.76 \%$. However, those needing blood transfusion accounted for $3.91 \%$ patients. Hydrothorax was present in $0.98 \%$ of patients. They were managed by intercostal tube drainage under local anesthesia. ${ }^{19}$ In the present study, only one patient in young age group required angiographic embolisation, impressively very low $(0.017 \%)$. According to a study by Kisa et al., no notable difference was found among ASA 1, 2, 3 groups with regard to duration of procedure and mean inpatient hospital stay. ${ }^{20}$ Furthermore, they deduced that there was no noteworthy dissimilarity regarding the complication rates among these groups. They further mentioned that when comparison was made according to Clavien classification system there were no significant differences in post-surgical complications among the younger and older patients in their cohort. ${ }^{21}$ Similar complication rates in group 1 and 2 were noted in the present study (Table III).

Reporting complications according to standard classifications is a better thing to gauge results of any center. Recent studies have depicted that percutaneous nephrolithotomy is an efficacious option for renal stones treatment. It can be performed with lower number of grave complications, especially if it is in experienced hands. ${ }^{22}$ The modified Clavien-Dindo classification system has efficient utilization for monitoring, reporting and comparisons of results of different surgeons and centers. ${ }^{21,22}$

The modified Clavien-Dindo classification of complications is a practical and easy tool for monitoring the percutaneous nephrolithotomy procedural results. ${ }^{20-22}$

This study had some strengths such as categorisation of complications on the basis of modified Clavian grading system to have standardised reporting of PCNL complications. Moreover, it had the largest number of elder age patients reported in literature and they were compared to younger age patients. However, it had some demerits as well such as being a retrospective study and a single center experience. There is no multicenter prospective study regarding the subject matter. So, multicenter experience is warranted.

\section{CONCLUSION}

This comparative study bolster up the notion of safety and effectiveness of PCNL in elderly age group alike as in the young age group patients. Itwas inferred herethat stone-free rates, complications and hospital stay were similar in the young and elder age group.

\section{ETHICALAPPROVAL:}

Ethical approval was taken from Institutional Review Board and Ethical Committee prior to commencing this study.

\section{PATIENTS' CONSENT:}

Informed consents were taken from all patients undergoing PCNL procedure. They were explained regarding the pros and cons of the procedure and the possible outcomes including the complications.

\section{CONFLICT OF INTEREST:}

The authors declared that there was no conflict of interest.

\section{AUTHORS' CONTRIBUTION:}

$\mathrm{NI}, \mathrm{AH}, \mathrm{HAM}, \mathrm{AN}, \mathrm{RK}, \mathrm{MAK}$ : Literature search.

AH, HAM, AN, RK: Data entry.

$\mathrm{NI}, \mathrm{AH}, \mathrm{HAM}, \mathrm{AN}$ : Data analysis.

$\mathrm{NI}, \mathrm{AH}, \mathrm{AN}, \mathrm{RK}$ : Writing.

$\mathrm{NI}, \mathrm{AH}, \mathrm{HAM}, \mathrm{MAK}$ : Editing and proofreading.

$\mathrm{NI}, \mathrm{AN}, \mathrm{RK}, \mathrm{MAK}$ : Critical review.

$\mathrm{NI}, \mathrm{AH}, \mathrm{HAM}, \mathrm{MAK}$ : Concept and design.

\section{REFERENCES}

1. Mitropoulos D, Artibani W, Biyani CS, Bjerggaard Jensen J, Rouprêt M, Truss M. Validation of the clavien-dindo grading system in urology by the european association of urology guidelines ad hoc panel. Eur Urol Focus 2018; 4(4):608-13. DOI: 10.1016/j.euf.2017.02.014. 
2. Knoll T, Schubert AB, Fahlenkamp D, Dietrich B Leusmann, Gunnar Wendt-Nordahl, Gernot Schubert. Urolithiasis through the ages: Data on more than 200,000 urinary stone analyses. J Urol 2011; 185(4):1304-11. doi: 10.1016/j.juro.2010.11.073.

3. Sorokin I, Mamoulakis C, Miyazawa K, Rodgers A, Talati J, Lotan Y. Epidemiology of stone disease across the world. World J Urol 2017; 35(9):1301-20. doi: 10.1007/ s00345-017-2008-6.

4. Wang WG, Babu SR, Wang L, Chen Y, Tian BL, He HB. Use of clavien-dindo classification in evaluating complications following pancreaticoduodenectomy in 1,056 cases: A retrospective analysis from one single institution. Oncol Lett 2018; 16(2):2023-2029. doi: 10.3892/ol.2018.8798.

5. Zhou X, Sun X, Chen X, Xiaoxin Gong, Yong Yang, Congbo Chen, et al. Effect of obesity on outcomes of percutaneous nephrolithotomy in renal stone management: A systematic review and meta-analysis. Urol Int 2017; 98(4):382-90. doi: $10.1159 / 000455162$.

6. Xu P, Wang J. Number of metabolic syndrome components is the central predictor of the impact of metabolic syndrome on outcome of percutaneous nephrolithotomy in staghorn nephrolithiasis. J Endourol 2019; 33(11):946-53. doi: 10.1089/end.2019.0404.

7. Seccombe A, Sapey E. What is the evidence base for fluid resuscitation in acute medicine? Clin Med (Lond) 2018; 18(3):225-30. doi: 10.7861/clinmedicine.18-3-225.

8. Ghani KR, Andonian S, Bultitude M, Desai M, Giusti G, Okhunov Z, et al. Percutaneous nephrolithotomy: update, trends, and future directions. Eur Urol 2016; 70(2):382-96. doi: 10.1016/j.eururo.2016.01.047.

9. Iqbal N, Assad S, Hussain I, Hassan Y, Khan H, Farooq MA, et al. Comparison of outcomes of tubed versus tubeless percutaneous nephrolithotomy in children: A single center study. Turk J Urol 2018; 44(1):56-61. doi:10.5152/tud. 2018.19616.

10. Cakici MC, Sari S, Selmi V, Sandikci F, Karakoyunlu N, Ozok $U$. Is the efficacy and safety of retrograde flexible ureteroscopy in the elderly population different from nonelderly adults? Cureus 2019; 11(6):e4852. doi: 10.7759/ cureus.4852.

11. Lamacchia GB, Korkes F, Baccaglini W, de Mello LGM, Szwarc M, Tobias-Machado M. A large series of extracorporeal shockwave lithotripsy in the very elderly. Ther Adv Urol 2019; 11:1756287219870412. doi: $10.1177 / 1756287219870412$.

12. Thomas K, Smith NC, Hegarty N, Glass JM. The Guy's stone score-grading the complexity of percutaneous nephrolithotomy procedures. Urology 2011; 78(2):277-81. doi: 10.1016/j.urology.2010.12.026.

13. Shohab D, Iqbal N, Alam MU, Butt A, Jamil MI, Hussain, Akhter S. Comparison of Outcome of Percutaneous Nephrolithotomy in Adult Versus Paediatric Patients. J Coll Physicians Surg Pak 2016; 26(5):371-3.

14. Johans CE, Bajic P, Kirshenbaum E, Blackwell RH, Kothari AN, Kuo PC, et al. Metabolic syndrome increases risk of postoperative myocardial infarction following percutaneous nephrolithotomy. J Endourol 2018; 32(11):1039-43. doi: 10.1089/end.2018.0519.

15. Sahin A, AstuN, Erdem E, Oner S, Bilen C, Bakkaloglu $M$, et al. Percutaneous nephrolithotomy in patients aged 60 years or older. J Endourol 2001; 15(5):489-9. doi: 10.1089/089277901750299276.

16. Okeke Z, Smith AD, Labate G, D Addessi A, Venkatesh R, Assimos D, et al. Prospective comparison of outcomes of percutaneous nephrolithotomy in elderly patients versus younger patients. J Endourol 2012; 26(8):996-1001. doi: 10.1089/end.2012.0046.

17. Ozturk H. Tubeless versus standard PCNL in geriatric population. Actas Urol ESP 2015; 39(8):494-501. doi: 10.1016/j.acuro.2015.02.010.

18. Krammbeck AE, Lieske JC, Li X, Bergstralh EJ, Melton LJ 3rd, Rule AD. Effect of age on the clinical presentation of incident symptomatic urolithiasis in the general population. J Urol 2013; 189(1):158-64. doi: 10.1016/j.juro.2012. 09.023.

19. Kumar S, Keshavamurthy R, Karthikeyan VS, Mallya A. Complications after prone PCNL in pediatric, adult and geri atric patients - a single center experience over 7 years. Int Braz J Urol 2017; 43(4):704-712. doi: 10.1590/S1677-5538. IBJU.2016.0563.

20. Kisa E, Yücel C, Budak S, Ucar M, Keskin MZ, Cakmak O, et al. The effect of the American society of anesthesiology classification scores on complications associated with percutaneous nephrolithotomy. Arch Ital Urol Androl 2018; 90(2):112-116. doi: 10.4081/aiua.2018.2.112.

21. Tawiński J, Jabłonowski Z. The analysis of perioperative complications of percutaneous nephrolithotomy in the treatment of nephrolithiasis with the use of modified Clavien-Dindo classification. Pol Merkur Lekarski 2018; 44(260): 49-53.

22. Torrecilla C, Vicéns-Morton AJ, Meza IA, Colom S, Etcheverry $B$, Vila $H$, et al. Complications of percutaneous nephrolithotomy in the prone position according with modified Clavien-Dindo grading system. Actas Urol Esp 2015; 39(3):169-74. doi: 10.1016/j.acuro.2014.07.006. 